\title{
Synthesis and Doping of a Multifunctional
}

\section{Tetrathiafulvalene-substituted Poly(isocyanide)}

Elba Gomar-Nadal, Laurent Mugica, José Vidal-Gancedo, Juan Casado, Juan T. López Navarrete, Jaume Veciana, Concepció Rovira, David B. Amabilino

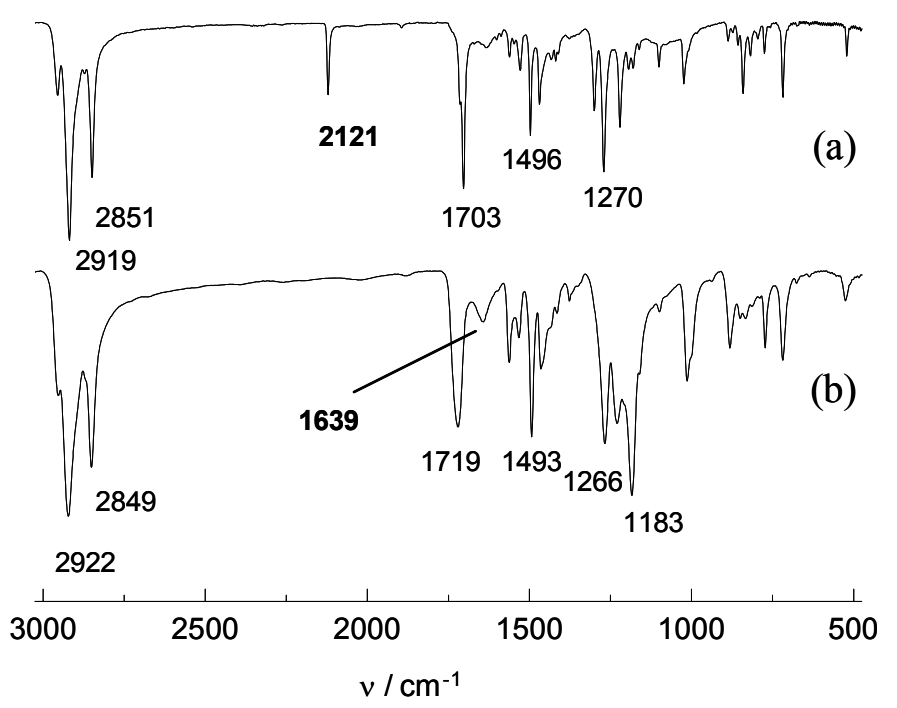

Figure S1: Infrared spectra of the: (a) monomer (5) and, (b) polymer (6). The IR spectra of the polymer showed no signal corresponding to the isocyanide moiety $\left(2121 \mathrm{~cm}^{-1}\right)$ and a broad band from the imine groups attached to the polymer backbone was observed at approximately $1639 \mathrm{~cm}^{-1}$. 


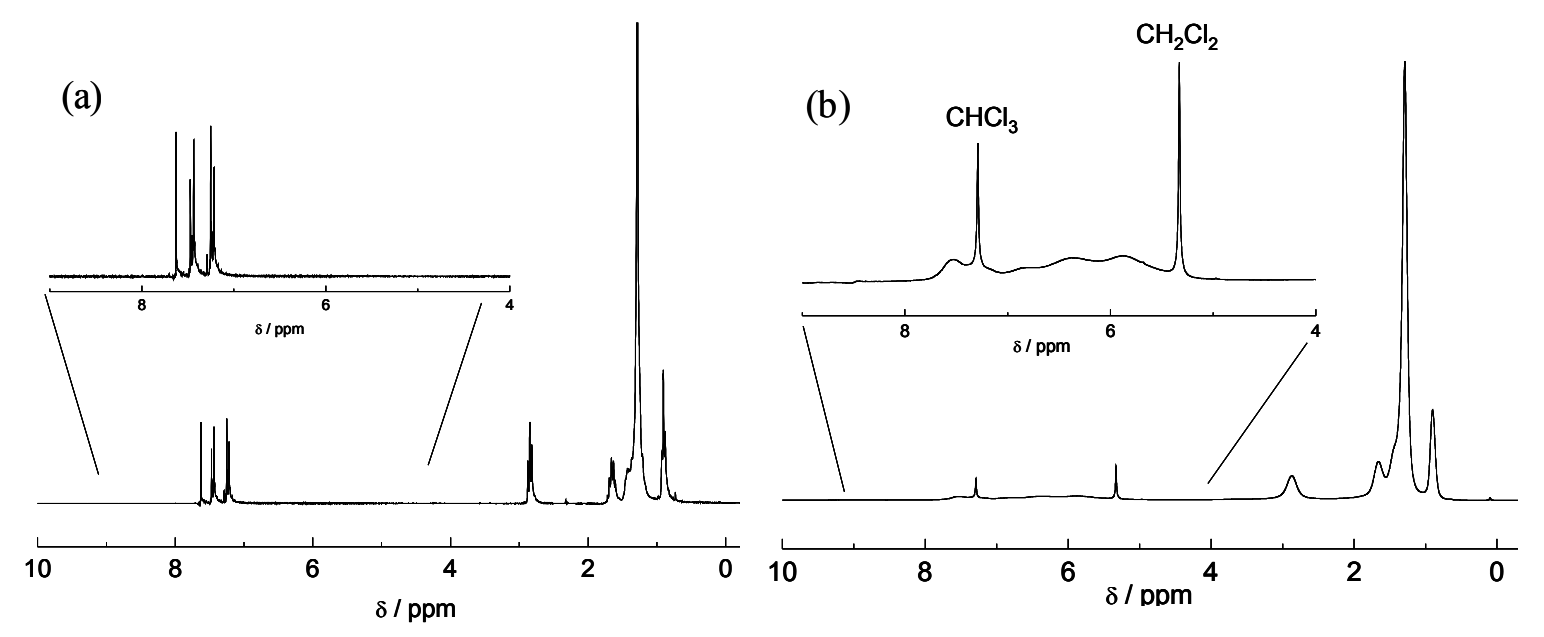

Figure S2: ${ }^{1} \mathrm{H}-\mathrm{NMR}\left(250 \mathrm{MHz}, \mathrm{CDCl}_{3}\right)$ spectra of the: (a) monomer (5) and, (b) polymer (6). The ${ }^{1} \mathrm{H}$ NMR of the polymer showed extremely broad resonances in the aromatic region from approximately 8.0 to 5.5 ppm corresponding to the phenyl benzoate moiety and $-\mathrm{CH}$ of the TTF unit. The high field position of the resonances arising from the aromatic groups, seen before in this type of polymers, is indicative of the proximity of the phenyl rings. The hydrogen atoms close to the polymer backbone are broad while those from the atoms in the aliphatic side chains of the macromolecule are more wellresolved, reflecting the higher mobility of the atoms at the end of the side chain. 


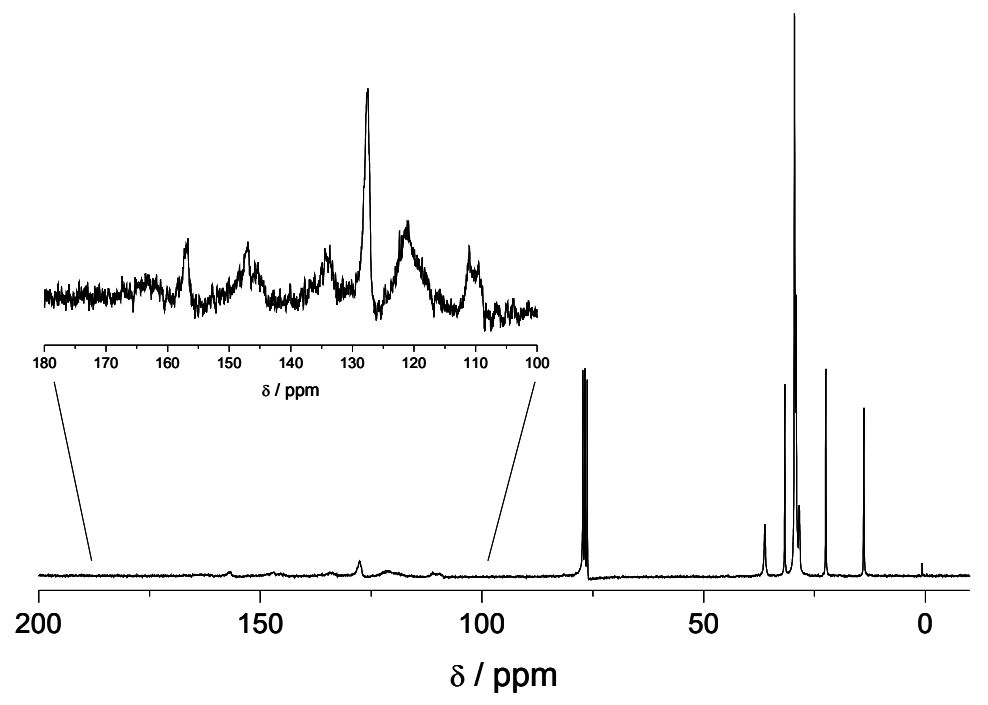

Figure S3: ${ }^{13} \mathrm{C}-\mathrm{NMR}\left(62.8 \mathrm{MHz}, \mathrm{CDCl}_{3}\right)$ spectrum of the polymer (6). The ${ }^{13} \mathrm{C}$ NMR spectra reveal similar characteristics to the ${ }^{1} \mathrm{H}$ NMR spectra with broad resonances arising from carbon atoms close to the polymer skeleton. In particular, the resonances arising from the carbon atoms in the skeleton itself is extremely broad (see supporting info), indicating the sterically hindred nature of the polymer core.
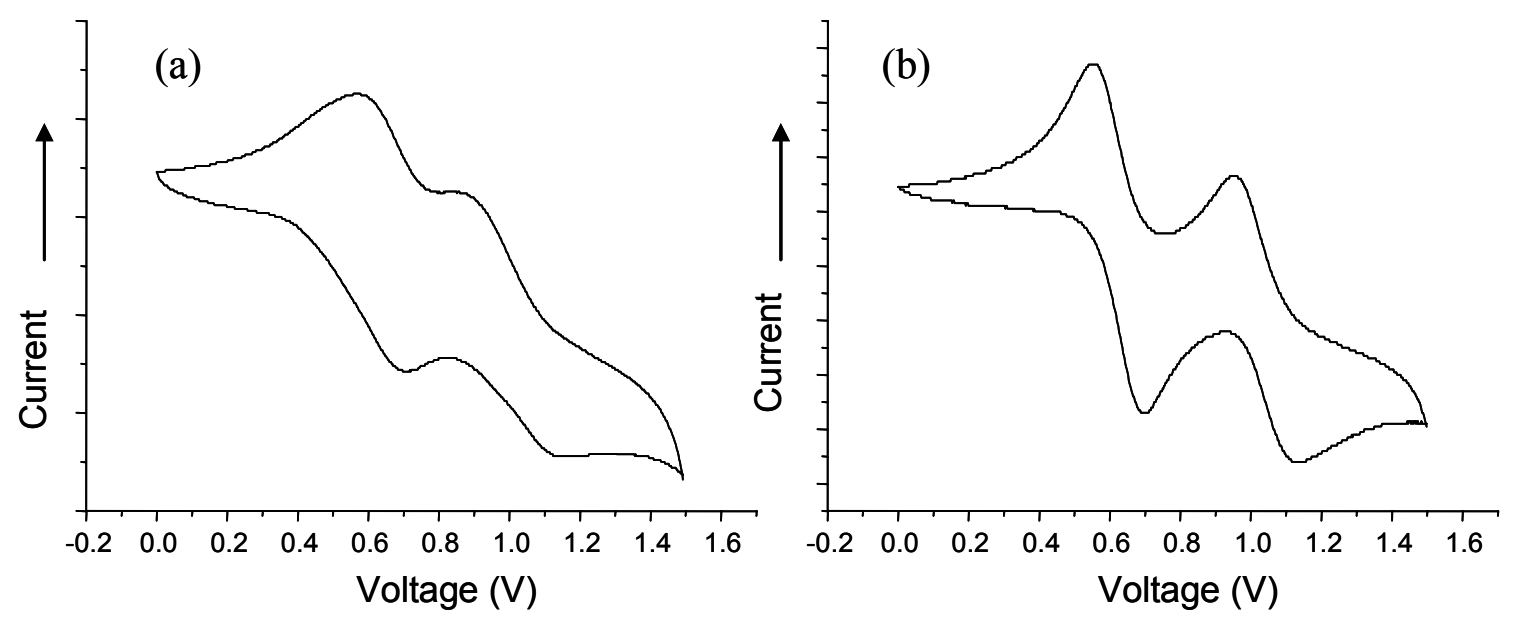

Figure S4: Cyclic voltamperometry $(\mathrm{CV})$ versus $\mathrm{Ag} / \mathrm{AgCl}$ recorded with $\left[\mathrm{NBu}_{4}\right]\left[\mathrm{PF}_{6}\right]$ in $\mathrm{CH}_{2} \mathrm{Cl}_{2}$ for: (a) polymer 6 and, b) compound 4. 


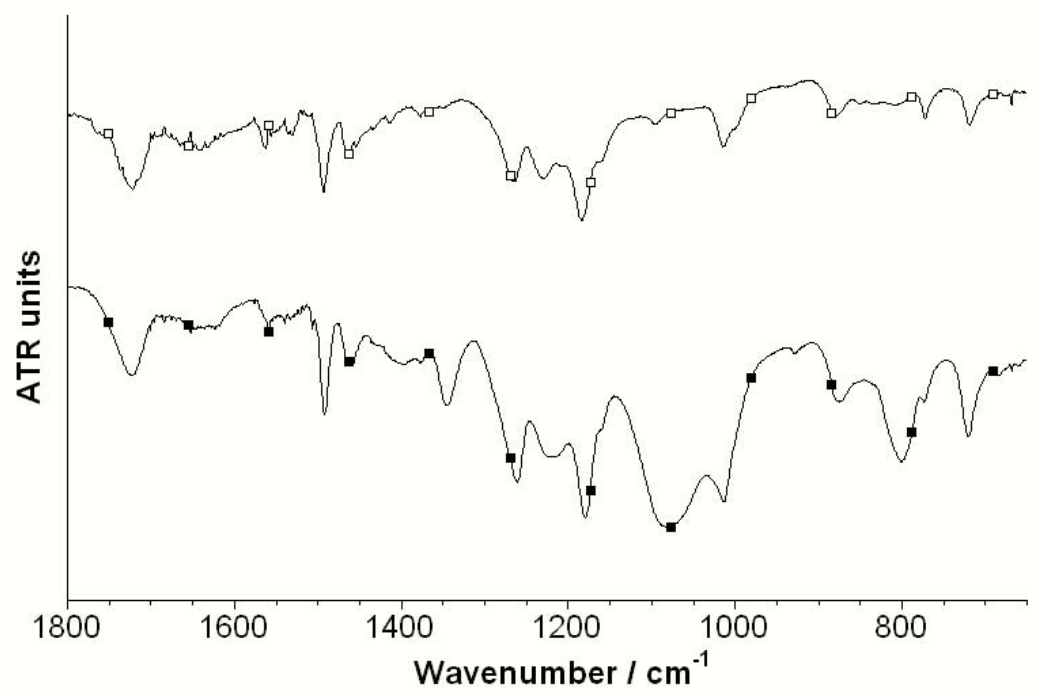

Figure S5. Comparison between the IR spectra of the neutral polymer ( $\square$ ) and of its oxidized form ( $\square$ ).

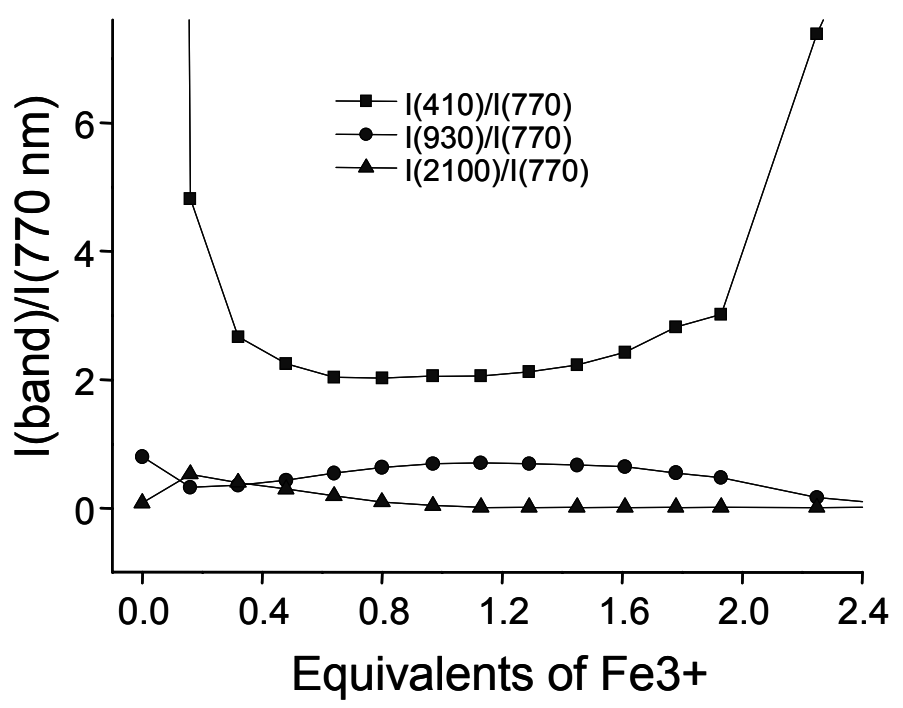

Figure S6: Plot of the normalized intensity with respect to the band at $770 \mathrm{~nm}$ for the bands at 410, 930 and $2100 \mathrm{~nm}$ versus the number equivalent of $\mathrm{Fe}^{3+}$. 


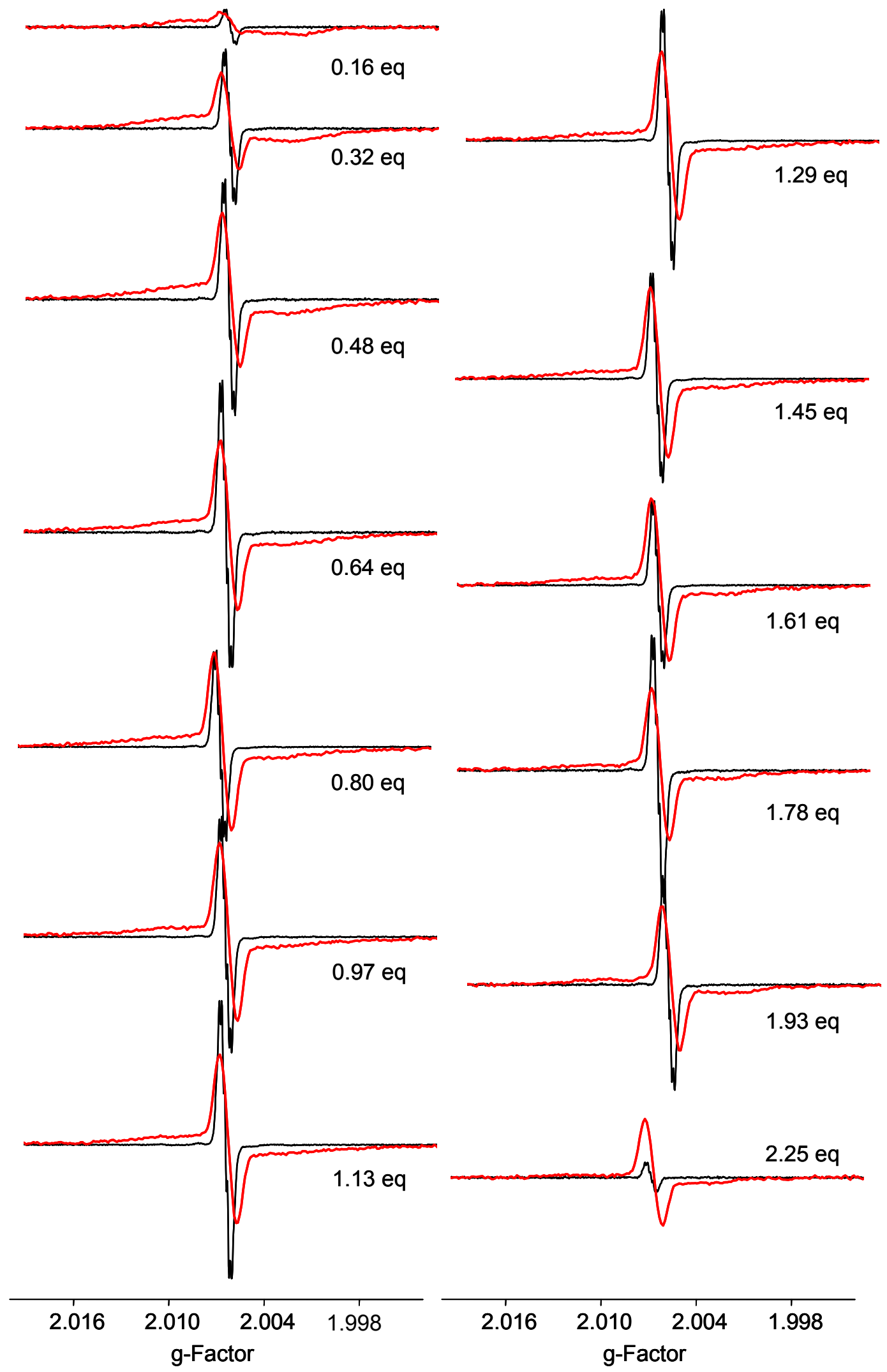

Figure S7: EPR signals of polymer 6 (red line) and compound 2 (black line) in $\mathrm{CH}_{2} \mathrm{Cl}_{2}: \mathrm{CH}_{3} \mathrm{CN} 7: 3$ at different doping levels of $\mathrm{Fe}\left(\mathrm{ClO}_{4}\right)_{3}$. 


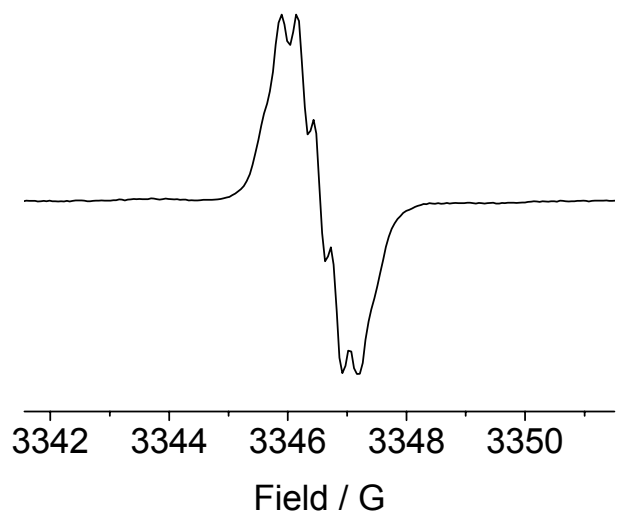

Figure S8: EPR spectrum of compound 2 in $\mathrm{CH}_{2} \mathrm{Cl}_{2}: \mathrm{CH}_{3} \mathrm{CN}$ 7:3 oxidized with 1.13 equivalents of $\mathrm{Fe}\left(\mathrm{ClO}_{4}\right)_{3}$.

\section{Doping with Halogens}

The evolution of the absorption spectra after adding different proportions of $\mathrm{Br}_{2}$ to a solution of the polymer has been monitored by both UV-Vis-NIR and FTIR spectroscopy.

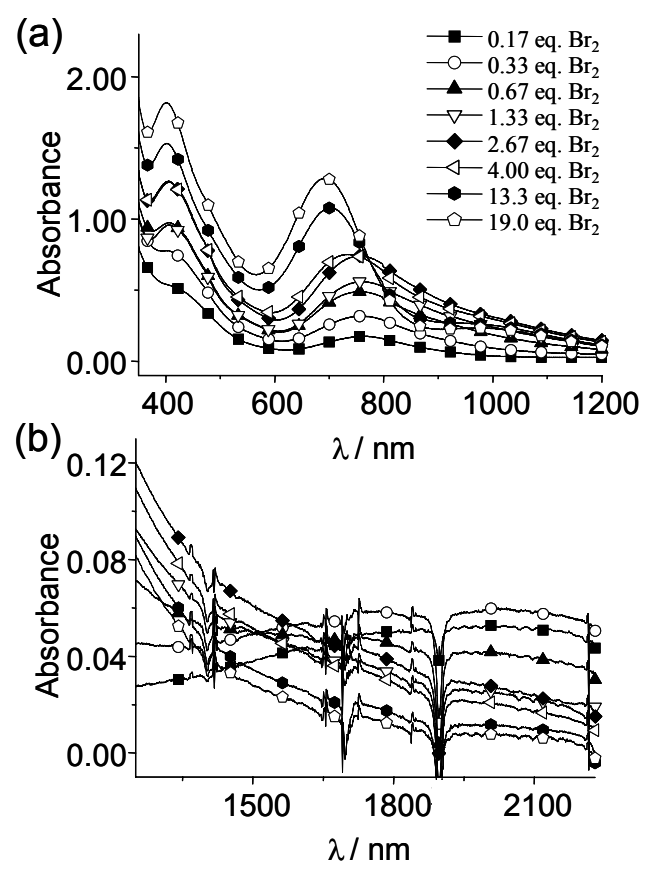

Figure S9: UV-Vis-NIR absorption spectra that show the evolution of the oxidation of polymer 6 in $\mathrm{CH}_{2} \mathrm{Cl}_{2}$ adding $\mathrm{Br}_{2}$ : (a) from 350 to $1200 \mathrm{~nm}$ and. (b) from 1200 to $2230 \mathrm{~nm}$. 


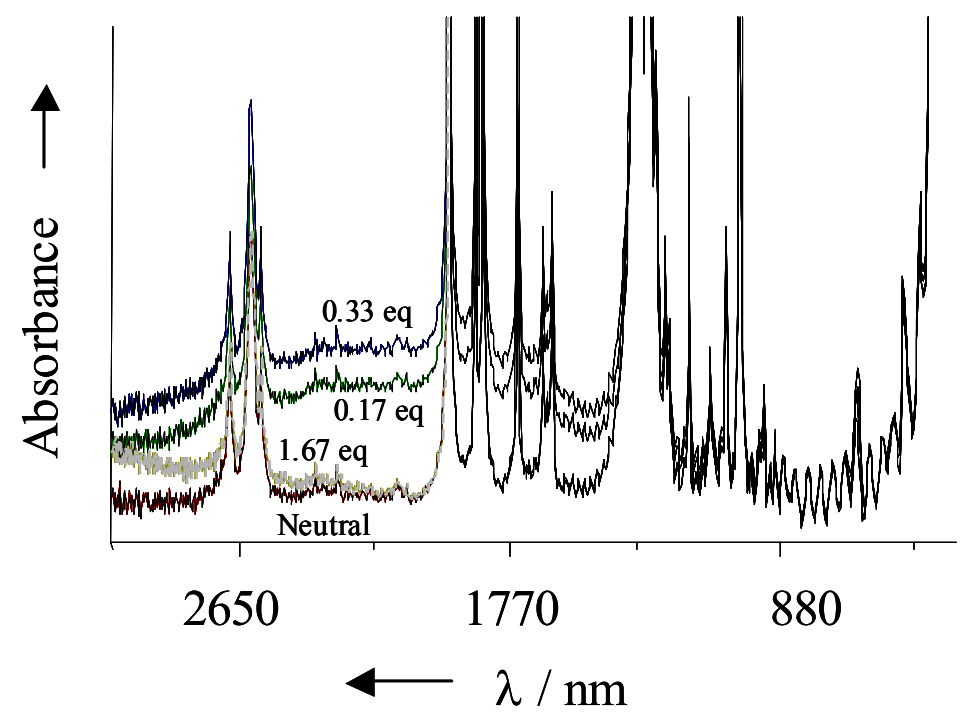

Figure S10: FT-NIR spectroscopy showing the evolution of the band centered at $2100 \mathrm{~nm}$ in solutions of polymer $6\left(1.16 \cdot \mathrm{m} \mathrm{M}\right.$ in $\left.\mathrm{CH}_{2} \mathrm{Cl}_{2}\right)$ using $\mathrm{Br}_{2}$ as oxidant. The base line is uncorrected.

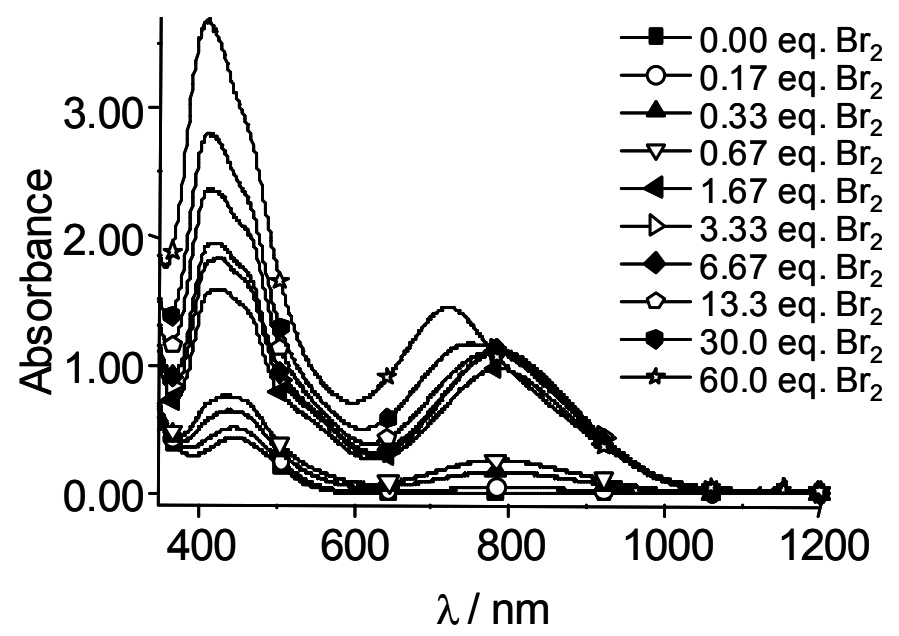

Figure S11: UV-Vis-NIR spectra that show the evolution of the oxidation of 4 in $\mathrm{CH}_{2} \mathrm{Cl}_{2}$ adding stoichiometrical amounts of $\mathrm{Br}_{2}$. 